\title{
Association study between miR-149 gene polymorphism and nasopharyngeal carcinoma
}

\author{
GUO-LIANG HUANG ${ }^{1,5^{*}}$, YAN LU ${ }^{1,5^{*}}$, XING-XIANG PU ${ }^{2 *}$, YU-XIANG HE ${ }^{3}$, \\ MEI-LING CHEN ${ }^{4}$, YA-ZHEN LI ${ }^{4}$, SHU-YIN TANG ${ }^{4}, \mathrm{HUA} \mathrm{CHE}^{4}$ and ZHIWEI HE ${ }^{1,5}$ \\ ${ }^{1}$ Sino-American Cancer Research Institute, Guangdong Medical College, Dongguan, Guangdong 523808; \\ ${ }^{2}$ Department of Medical Oncology, Hunan Tumor Hospital, Changsha, Hunan 410006; ${ }^{3}$ Department of Oncology, \\ Central South University Xiangya Hospital, Changsha, Hunan 410011; ${ }^{4}$ Institute of Laboratory Medicine, \\ Guangdong Medical College; ${ }^{5}$ Key Laboratory for Medical Molecular Diagnostics of Guangdong, \\ Dongguan, Guangdong 523808, P.R. China
}

Received February 22, 2013; Accepted April 12, 2013

DOI: 10.3892/br.2013.97

\begin{abstract}
Association studies between single-nucleotide polymorphism (SNP) rs2292832 on miR-149 gene and cancer risk have been previously analyzed in several types of cancer. The aim of this study was to evaluate the association between miR-149 polymorphism and risk of nasopharyngeal carcinoma (NPC). miR-149 gene polymorphism was genotyped using polymerase chain reaction (PCR)-restriction fragment length polymorphism (RFLP) in 158 patients with NPC and 242 healthy individuals. Associations with cancer risk and clinicopathological characteristics were analyzed by $\chi^{2}$ test. No significant difference was observed for miR-149 gene polymorphism in NPC patients and healthy controls in either genotype $(\mathrm{P}=0.427$ for $\mathrm{CC}$ vs. $\mathrm{CT}$ vs. $\mathrm{TT}, \mathrm{P}=0.247$ for CT vs. TT and $\mathrm{P}=0.323$ for $\mathrm{CC}$ vs. TT, respectively) or allelic analysis $(\mathrm{P}=0.216)$. No significant difference was noted between the genotypes and the clinicopathological parameters examined with the exception of clinical stage. A significantly higher CC distribution in clinical stage I-II compared with III-IV was observed under the dominant model (CC vs. CT vs. TT, $\mathrm{P}=0.026)$ and the co-dominant model (CC vs. TT, $\mathrm{P}=0.030$ ). The results of this study suggested that the $\mathrm{CC}$ genotype of miR-149 contributes to the progression and development, rather than the initiation of NPC.
\end{abstract}

Correspondence to: Professor Zhiwei He, Sino-American Cancer Research Institute, Guangdong Medical College, 1 Xincheng Road, Dongguan, Guangdong 523808, P.R. China

E-mail: zhiweihe688@yahoo.com

*Contributed equally

Key words: cancer risk, miR-149, nasopharyngeal carcinoma, polymorphism, single-nucleotide polymorphism

\section{Introduction}

Nasopharyngeal carcinoma (NPC) is an epithelial malignancy with an unusual ethnic and geographic disparity. It has been estimated that $92 \%$ of new cases occur in economically developing countries (1). High incidence is observed in Malaysia, Indonesia, Singapore, a number of provinces in South-Eastern China, including Guangdong and Hong Kong, and in other parts of Southern Asia (1,2). Aetiological factors for NPC carcinogenesis include genetic susceptibility, early-age exposure to chemical carcinogens (particularly Cantonese salted fish), and latent Epstein-Barr virus (EBV) infection (3). A few genes were reported to contribute to the risk of NPC by genetic linkage and association studies (4-6). However, the precise genetic alterations during NPC carcinogenesis remain to be clarified.

MicroRNAs (miRNAs) are a large family of gene regulators that have been shown to repress the expression of important cancer-related genes and might be useful in the diagnosis and treatment of cancer (7). The association between microRNA polymorphism and cancer risk or tumor clinicopathological characteristics has been reported in a number of studies. The SNP rs11614913 in hsa-miR-196a2 gene was associated with patient survival in non-small cell lung cancer (8). A significant association between miR-196a 2 polymorphism and risk of digestive system cancers, particularly of colorectal and hepatocellular cancer, was identified (9). A significant association between single-nucleotide polymorphism (SNP) rs2910164 in miR-146a gene and an increased risk of gastric (10) and breast (11) cancer was also identified.

Association studies between SNP rs2292832 on miR-149 gene and cancer risk were analyzed in several types of cancer, including lung cancer $(8,12,13)$, breast cancer $(14)$, squamous cell carcinoma of the head and neck (15), gastric cancer and colorectal cancer $(16,17)$. miR-149 CT/CC genotype carriers had increased susceptibilities to colorectal cancer among those that engaged in smoke inhalation, whereas a significantly protective effect of miR-149 CT/CC on the incidence of gastric cancer exists among tea drinkers (16). However, to the best of our knowledge, no previous study has reported on the association 
Table I. Characteristics of patients and controls.

\begin{tabular}{|c|c|c|c|}
\hline Characteristics & Patients & Controls & P-value \\
\hline Mean age (mean $\pm \mathrm{SD}$, years) & $46.6 \pm 11.1$ & $47.2 \pm 10.5$ & 0.588 \\
\hline \multicolumn{4}{|l|}{ Age (years) } \\
\hline$<45$ & 77 & 112 & \multirow[t]{2}{*}{0.631} \\
\hline$\geq 45$ & 81 & 130 & \\
\hline \multicolumn{4}{|l|}{ Gender } \\
\hline Male & 111 & 157 & \multirow[t]{2}{*}{0.264} \\
\hline Female & 47 & 85 & \\
\hline \multicolumn{4}{|l|}{ T stage $\mathrm{a}^{\mathrm{a}}$} \\
\hline $\mathrm{T} 1-\mathrm{T} 2$ & 51 & - & \\
\hline T3-T4 & 102 & - & \\
\hline \multicolumn{4}{|l|}{ N stage ${ }^{a}$} \\
\hline N0 & 9 & - & \\
\hline N1-N2-N3 & 144 & & \\
\hline \multicolumn{4}{|l|}{ Metastasis $^{\mathrm{a}}$} \\
\hline No & 140 & - & \\
\hline Yes & 10 & - & \\
\hline \multicolumn{4}{|l|}{ Clinical stage $^{\mathrm{a}}$} \\
\hline I-II & 10 & - & \\
\hline III-IV & 145 & - & \\
\hline
\end{tabular}

${ }^{a}$ The sum of certain characteristics does not equal the total number of patients due to unavailable data. SD, standard deviation.

between miR-149 polymorphism and NPC risk. To elucidate the NPC molecular mechanism, the association between SNP rs2292832 on miR-149 gene and risk of NPC was evaluated in this study.

\section{Materials and methods}

Study population. This case-control study included 158 patients with nasopharyngeal carcinoma (NPC) and 242 healthy individuals undergoing routine medical examination without any medical illness in the Hunan Tumor Hospital between April and October, 2011. The patients were diagnosed via histopathological evidence. The subjects were unrelated ethnic Chinese adults, who were resident in Changsha City (Changsha, China) or the surrounding regions. Informed consent was obtained from all participants for the use of their blood samples in the present study. This study was approved by the institutional review board of Hunan Tumor Hospital.

Genotyping assay. The SNP rs2292832 on miR-149 gene, which was reported to be associated with tumor risk for genotyping was selected $(8,16)$. Genomic DNA was extracted from the whole blood of all participants, then genotyped using polymerase chain reaction (PCR)-restriction fragment length polymorphism (RFLP). The PCR mixture consisted of 5 pmol of each primer, 1X GoTaq Master Mix (Promega Corporation, Madison, WI, USA) and $2.0 \mu \mathrm{l}$ extracted DNA at a total volume of $15 \mu \mathrm{l}$. The PCR procedure included an initial melting step at $95^{\circ} \mathrm{C}$ for $5 \mathrm{~min}$, then 30 cycles at $95^{\circ} \mathrm{C}$ for $30 \mathrm{sec}$, at $60^{\circ} \mathrm{C}$ for $30 \mathrm{sec}$, at $72^{\circ} \mathrm{C}$ for $1 \mathrm{~min}$ and a final extension step at $72^{\circ} \mathrm{C}$ for $10 \mathrm{~min}$. The primers for PCR amplification were as follows (8): forward, 5'-TGT CTT CAC TCC CGT GCT TGT CC-3' and reverse, 5'-TGA GGC CCG AAA CAC CCG TA-3'. The PCR product of 254 base pairs (bp) (the CC genotype) was digested by $P v u I I$ (Promega Corporation) into fragments of 194 and $60 \mathrm{bp}$ for TT and into fragments of 254, 194 and $60 \mathrm{bp}$ for CT. PCR products were randomly selected for DNA sequencing validation.

Statistical analysis. The Hardy-Weinberg equilibrium was utilized to compare the observed with expected genotype frequencies in the control groups. Genotype and allele frequencies were compared between patients and controls using the $\chi^{2}$ test. Odds ratios and $95 \%$ confidence intervals for the risk of NPC were calculated to estimate the relative risk using the multivariate logistic regression analysis adjusted by age and gender. The $\chi^{2}$ test or Fisher's exact test was performed in a subsequent analysis of the association between the polymorphisms and clinical characteristics where appropriate. Statistical analyses were performed with SPSS 16.0 software. $\mathrm{P}<0.05$ was considered to indicate a statistically significant difference and all statistical analyses were two-sided.

\section{Results}

Characteristics of patients with NPC and healthy controls. A total of 400 samples were included in this case-control study, including 158 patients with NPC and 242 healthy controls (Table I). Age and gender did not show a statistically different 
Table II. Genotype and allele distribution of rs2292832 in patients and controls.

\begin{tabular}{|c|c|c|c|c|c|c|}
\hline Polymorphism & Patient & Control & $\chi^{2}$ & P-value & OR & $95 \% \mathrm{CI}$ \\
\hline \multicolumn{7}{|l|}{ rs2292832 T>C } \\
\hline \multicolumn{7}{|l|}{ Genotype } \\
\hline $\mathrm{CC}$ & $22(13.9)$ & $39(16.1)$ & 1.702 & 0.427 & & \\
\hline $\mathrm{CT}$ & $67(42.4)$ & 113 (46.7) & & & & \\
\hline $\mathrm{TT}$ & $69(43.7)$ & $90(37.2)$ & & & & \\
\hline CT vs. TT & & & 1.34 & 0.247 & $0.761^{\mathrm{a}}$ & 0.491-1.179 \\
\hline CC vs. TT & & & 0.977 & 0.323 & $1.023^{\mathrm{a}}$ & $0.754-1.387$ \\
\hline \multicolumn{7}{|l|}{ Allele } \\
\hline $\mathrm{C}$ & $111(35.1)$ & $191(39.5)$ & 1.53 & 0.216 & 0.831 & $0.619-1.115$ \\
\hline $\mathrm{T}$ & 205 (64.9) & $293(60.5)$ & & & & \\
\hline
\end{tabular}

${ }^{\text {aD }}$ ata were calculated by unconditional logistic regression with adjustment for age and gender. OR, odd ratio; CI, confidence interval.

Table III. Clinicopathological characteristics and the genotypes of rs2292832 in nasopharyngeal carcinoma patients.

\begin{tabular}{|c|c|c|c|c|c|}
\hline \multirow[b]{2}{*}{ Parameters } & \multicolumn{3}{|c|}{ rs2292832 } & \multirow[b]{2}{*}{ P-value } & \multirow[b]{2}{*}{ P-value (CC vs. TT) } \\
\hline & $\mathrm{CC}$ & $\mathrm{CT}$ & TT & & \\
\hline \multicolumn{6}{|l|}{ Age (years) } \\
\hline$<45$ & $8(10.7)$ & $28(37.3)$ & $39(52.0)$ & 0.121 & 0.099 \\
\hline$\geq 45$ & $14(16.9)$ & $39(47.0)$ & $30(36.1)$ & & \\
\hline \multicolumn{6}{|l|}{ Gender } \\
\hline Male & $16(14.0)$ & $50(43.9)$ & $48(42.1)$ & 0.803 & 0.777 \\
\hline Female & $6(13.6)$ & $17(38.6)$ & $21(47.7)$ & & \\
\hline \multicolumn{6}{|l|}{ T stage } \\
\hline $\mathrm{T} 1-\mathrm{T} 2$ & $7(13.7)$ & $25(49.0)$ & $19(37.3)$ & 0.386 & 0.757 \\
\hline T3-T4 & $15(14.9)$ & $38(37.6)$ & $48(47.5)$ & & \\
\hline \multicolumn{6}{|l|}{ N stage } \\
\hline N0 & $3(33.3)$ & $4(44.4)$ & $2(22.2)$ & 0.182 & 0.094 \\
\hline N1-N2-N3 & $19(13.3)$ & $59(41.3)$ & $65(45.5)$ & & \\
\hline \multicolumn{6}{|l|}{ Metastasis } \\
\hline No & $21(15.1)$ & $57(41.0)$ & $61(43.9)$ & 0.884 & 1.000 \\
\hline Yes & $1(10.0)$ & $4(40.0)$ & $5(50.0)$ & & \\
\hline \multicolumn{6}{|l|}{ Clinical stage } \\
\hline I-II & $4(44.4)$ & $3(33.3)$ & $2(22.2)$ & 0.026 & 0.030 \\
\hline III-IV & $18(12.4)$ & $61(42.1)$ & $66(45.5)$ & & \\
\hline
\end{tabular}

distribution in patients and controls. Most patients were in the late stage disease as shown in clinical stage (Table I).

Distribution of genotype and allele frequencies and their association with risk of NPC. Genotype distribution of the SNP rs2292832 in the control group was in accordance with the Hardy-Weinberg ( $>>0.05)$, suggesting the genetic equilibrium of the population enrolled (Table II). The frequencies of genotype CC, CT and TT of rs2292832 were 13.9, 42.4 and $43.7 \%$, respectively, in the patient group, and 16.1, 46.7 and $37.2 \%$, respectively, in the control group. The allele frequen- cies for $\mathrm{C}$ and $\mathrm{T}$ were 35.1 and $64.9 \%$, respectively, in the patient group, and 39.5 and $60.5 \%$, respectively, in the control group. The SNP rs2292832 on miR-149 showed no significant difference between NPC patients and healthy controls in either genotype $(\mathrm{P}=0.427$ for $\mathrm{CC}$ vs. $\mathrm{CT}$ vs. TT, $\mathrm{P}=0.247$ for CT vs. TT and $\mathrm{P}=0.323$ for $\mathrm{CC}$ vs. TT, respectively, Table II) or allelic analysis $(\mathrm{P}=0.216$, Table II) for the comparison models.

Association between genotypes and clinicopathological characteristics of NPC. We analyzed the clinicopathological characteristics to investigate whether there was any association 
between the genotype distribution and NPC progression. The clinicopathological parameters for comparison including primary tumor extension, regional lymph node status, metastatic status and clinical stages were dichotomized as follows: The primary tumor extension, T1-T2 vs. T3-T4; the regional lymph node status N0 vs. N1-N2-N3; the metastatic status, negative vs. positive and the clinical stages I-II vs. III-IV. No significant difference was found between the genotypes and clinicopathological parameters examined, with the exception of clinical stage. A significant higher CC distribution in clinical stage I-II vs. III-IV was observed under the dominant model (CC vs. CT vs. TT, $\mathrm{P}=0.026$, Table III) and the co-dominant model (CC vs. TT, $\mathrm{P}=0.030$, Table III).

\section{Discussion}

miR-149 was reported to be downregulated in various types of cancer, including squamous cell carcinoma of tongue (18), clear cell renal cell carcinoma (19), prostate carcinoma (20) and astrocytomas (21). A pattern of six miRNAs containing miR-149 received an overall correction rate of $80 \%$ in the diagnosis of prostate carcinoma (20). miR-149 expression levels were negatively correlated with the WHO grade in astrocytomas (21). Overexpression of miR-149 inhibited glioblastoma cell proliferation and migration (21). miRNA-149 inhibited the proliferation and cell cycle progression in human gastric cancer (22). These results suggested miR-149 was a tumor suppressor. However, in NPC, an upregulated miR-149 level was reported in tumor tissue (23) and NPC cell lines (24). miR-149 promoted the proliferation, invasion and mobility of NPC cell lines (24). Thus, miR-149 appeared to function as a tumor promoter of NPC.

The single nucleotide polymorphism of miR-149 gene was first reported by $\mathrm{Hu}$ et al (8). These authors analyzed the relationship between the polymorphism and non-small cell lung cancer survival, however no significant association was identified. Association studies between miR-149 polymorphism and cancer risk were reported for several types of cancer. Significant associations were observed in colorectal and gastric cancer (16). In this study, we genotyped the SNP rs2292832 on miR-149 gene in 158 patients with NPC and 242 healthy controls. No associations were observed between NPC patients and healthy controls in either the genotype or allelic analysis for the comparison models. The result is similar to the studies conducted on lung cancer $(8,12,13)$, breast cancer (14), squamous cell carcinoma of the head and neck (15), and colorectal cancer in a Korean population (17), where no association between miR-149 polymorphism with cancer risk was observed. In the study of squamous cell carcinoma of the head and neck by Liu et al (15), a combined risk genotype of four SNPs on miR-146a, miR-149, miR-196a2 and miR-499 was found to be significantly associated with cancer risk, although miR-149 polymorphism alone did not prove to be significant.

The association between genotypes and clinicopathological parameters of NPC was also analyzed. A significant higher $\mathrm{CC}$ distribution in clinical stage I-II compared with III-IV was observed for the dominant model (CC vs. CT vs. TT) and the co-dominant model (CC vs. TT). In the study of lung cancer, CC genotype of miR-149 demonstrated a significant maximal expression in tumor tissue (13). A maximal, but not significant expression of CC genotype was observed in gastrointestinal cancer and other types of intestinal mucosal tissue samples (16). In that study on gastrointestinal cancer miR-149 CT/CC genotype carriers were found to have increased susceptibilities to colorectal cancer among those that engaged in smoke inhalation; whereas a significantly protective effect of miR-149 CT/CC on gastric cancer incidence exists among tea drinkers (16). The results suggested that the $\mathrm{CC}$ genotype was able to regulate the expression of miR-149 and therefore affect cancer risk or cancer progression.

In this study, no significant association was observed between miR-149 polymorphism and NPC risk. However, $\mathrm{CC}$ distribution was significantly higher in clinical stage I-II compared with III-IV in the clinicopathological parameter analysis. The results suggested that the CC genotype contributes to the progression and development, rather than the initiation of NPC.

\section{Acknowledgements}

This study was supported by the National Natural Science Foundation of China (nos. 30672379 and 30973374 to Z.H.), Natural Science Foundation of Guangdong Province (to Z.H.), Science and Technology Innovation Fund of Guangdong Medical College (no. STIF201108 to Z.H.), Medical Science Research Foundation of Guangdong Province (no. B2011232 to G-L H), and National Natural Science Foundation of China (no. 81102048 to G.H.).

\section{References}

1. Jemal A, Bray F, Center MM, Ferlay J, Ward E and Forman D: Global cancer statistics. CA Cancer J Clin 61: 69-90, 2011.

2. Guigay J: Advances in nasopharyngeal carcinoma. Curr Opin Oncol 20: 264-269, 2008.

3. Tao Q and Chan AT: Nasopharyngeal carcinoma: molecular pathogenesis and therapeutic developments. Expert Rev Mol Med 9: 1-24, 2007.

4. Feng BJ, Huang W, Shugart YY, et al: Genome-wide scan for familial nasopharyngeal carcinoma reveals evidence of linkage to chromosome 4. Nat Genet 31: 395-399, 2002.

5. Zhou G, Zhai Y, Cui Y, et al: MDM2 promoter SNP309 is associated with risk of occurrence and advanced lymph node metastasis of nasopharyngeal carcinoma in Chinese population. Clin Cancer Res 13: 2627-2633, 2007.

6. Zhang Y, Zhang H, Zhai Y, et al: A functional tandem-repeats polymorphism in the downstream of TERT is associated with the risk of nasopharyngeal carcinoma in Chinese population. BMC Med 9: 106, 2011.

7. Esquela-Kerscher A and Slack FJ: Oncomirs-microRNAs with a role in cancer. Nat Rev Cancer 6: 259-269, 2006.

8. Hu Z, Chen J, Tian T, et al: Genetic variants of miRNA sequences and non-small cell lung cancer survival. J Clin Invest 118: 2600-2608, 2008.

9. Guo J, Jin M, Zhang $M$ and Chen K: A genetic variant in miR-196a2 increased digestive system cancer risks: a meta-analysis of 15 case-control studies. PLoS One 7: e30585, 2012.

10. Zhou F, Zhu H, Luo D, et al: A functional polymorphism in Pre-miR-146a is associated with susceptibility to gastric cancer in a Chinese population. DNA Cell Biol 31: 1290-1295, 2012.

11. Lian H, Wang L and Zhang J: Increased risk of breast cancer associated with CC genotype of Has-miR-146a Rs2910164 polymorphism in Europeans. PLoS One 7: e31615, 2012.

12. Tian T, Shu Y, Chen J, et al: A functional genetic variant in microRNA-196a2 is associated with increased susceptibility of lung cancer in Chinese. Cancer Epidemiol Biomarkers Prev 18: 1183-1187, 2009. 
13. Vinci S, Gelmini S, Pratesi N, et al: Genetic variants in miR-146a, miR-149, miR-196a2, miR-499 and their influence on relative expression in lung cancers. Clin Chem Lab Med 49: 2073-2080, 2011.

14. Zhang M, Jin M, Yu Y, et al: Associations of miRNA polymorphisms and female physiological characteristics with breast cancer risk in Chinese population. Eur J Cancer Care (Engl) 21: 274-280, 2012.

15. Liu Z, Li G, Wei S, et al: Genetic variants in selected pre-microRNA genes and the risk of squamous cell carcinoma of the head and neck. Cancer 116: 4753-4760, 2010.

16. Zhang MW, Jin MJ, Yu YX, et al: Associations of lifestyle-related factors, hsa-miR-149 and hsa-miR-605 gene polymorphisms with gastrointestinal cancer risk. Mol Carcinog 51 (Suppl 1): E21-E31, 2012.

17. Min KT, Kim JW, Jeon YJ, et al: Association of the miR-146aC> G $149 \mathrm{C}>\mathrm{T}, 196 \mathrm{a} 2 \mathrm{C}>\mathrm{T}$, and $499 \mathrm{~A}>\mathrm{G}$ polymorphisms with colorectal cancer in the Korean population. Mol Carcinog 51 (Suppl 1): E65-E73, 2012.

18. Wong TS, Liu XB, Wong BY, Ng RW, Yuen AP and Wei WI: Mature miR-184 as potential oncogenic microRNA of squamous cell carcinoma of tongue. Clin Cancer Res 14: 2588-2592, 2008.
19. Liu H, Brannon AR, Reddy AR, et al: Identifying mRNA targets of microRNA dysregulated in cancer: with application to clear cell renal cell carcinoma. BMC Syst Biol 4: 51,2010.

20. Schaefer A, Jung M, Mollenkopf HJ, et al: Diagnostic and prognostic implications of microRNA profiling in prostate carcinoma. Int J Cancer 126: 1166-1176, 2010.

21. Li D, Chen P, Li XY, et al: Grade-specific expression profiles of miRNAs/mRNAs and docking study in human grade I-III astrocytomas. Omics 15: 673-682, 2011.

22. Wang Y, Zheng X, Zhang Z, et al: MicroRNA-149 inhibits proliferation and cell cycle progression through the targeting of ZBTB2 in human gastric cancer. PLoS One 7: e41693, 2012.

23. Luo Z, Zhang L, Li Z, et al: An in silico analysis of dynamic changes in microRNA expression profiles in stepwise development of nasopharyngeal carcinoma. BMC Med Genomics 5: 3, 2012.

24. Luo Z, Zhang L, Li Z, et al: miR-149 promotes epithelial-mesenchymal transition and invasion in nasopharyngeal carcinoma cells. Zhong Nan Da Xue Xue Bao Yi Xue Ban 36: 604-609, 2011. 